\title{
Estudo das tensões residuais em juntas soldadas de materiais dissimilares e determinação dos limites de resistência à fadiga dos metais de base
}

(Study of residual stress in welds of dissimilar material and determination of fatigue strength limits of base metals)

Tanius Rodrigues Mansur ${ }^{l}$, Nelson do N. Atanazio Filhol, Paulo de Tarso Vida Gomes ${ }^{1}$, Emerson Giovani Rabello ${ }^{l}$, Luiz Leite da Silval, Geraldo Antônio Scoralick ${ }^{1}$, Mariana Coelho de Vasconcelos Santos ${ }^{1}$, Alexandre Queiroz Bracarense ${ }^{2}$

${ }^{1}$ Centro de Desenvolvimento da Tecnologia Nuclear - CDTN, Belo Horizonte, MG, Brasil, tanius@cdtn.br

${ }^{2}$ Universidade Federal de Minas Gerais - UFMG, Belo Horizonte, MG, Brasil, bracarense@ufmg.br

\section{Resumo}

A soldagem de metais dissimilares tem diversas aplicações na indústria. Notadamente na indústria alimentícia e na indústria nuclear, este tipo de junta, comum entre aço carbono A36 e aço inoxidável austenístico ou entre aço inoxidável austenístico e cobre e suas ligas, é sempre motivo de análise e cuidados especiais tendo em vista a necessidade de manter a integridade dos equipamentos. Variações térmicas e dimensionais durante o uso de equipamentos que possuem juntas de materiais dissimilares são sempre preocupantes porque nem sempre se conhece o histórico da fabricação ou mesmo da execução de alguma recuperação, dificultando o gerenciamento do envelhecimento. O conhecimento antecipado destas variações por meio do conhecimento da vida a fadiga pode contribuir muito no projeto, na escolha do processo de fabricação, na escolha do consumível de soldagem e obviamente na conservação e integridade do equipamento. Apresentam-se neste trabalho os resultados obtidos para as tensões residuais nas soldas dissimilares e as curvas $S$ - $N$-P que relacionam tensão com o número de ciclos e a probabilidade de falha, para 4 metais: cobre eletrolítico, aço inoxidável AISI 304, aço inoxidável AISI $316 \mathrm{~L}$ e aço carbono A36 que foram posteriormente soldados entre si.

Palavras-chave: Soldagem de metais dissimilares, limite de resistencia a fadiga, tensões residuais de soldas, curvas SNP.

Abstract: The welding of dissimilar metals has many applications in industry. In special, in the food industry and nuclear industry, this type of joint, common between A36 carbon steel and austenitic stainless steel or between austenitic stainless steel and copper and its alloys, is always subject to analysis and special care to maintain equipments integrity. Thermal and dimensional variations during use of equipment that have dissimilar welds are always troubling because not always it is known the history of the manufacture or recovery, making the management of aging difficult. Advance knowledge of these variations through the knowledge of the fatigue life can greatly contribute in design, choice of manufacturing process, choice of consumables and obviously in the preservation and integrity of the equipment. This paper presents results achieved for the residual stresses in dissimilar welds and SNP curves relating tension with the number of cycles and the failure probability for four metals: electrolytic copper, austenitic AISI 304 and AISI 316L stainless steels and A36 carbon steel which were subsequently welded together.

Key-words: Welding of dissimilar metals, fatigue strength limit, residual stress of welds, SNP curves.

\section{Introdução}

Pode-se definir a fadiga como sendo o processo de degradação localizada, progressiva e permanente, que ocorre em material sujeito a variações de tensões e deformações e que produzem a nucleação de trincas ou a completa fratura depois de um número suficiente de ciclos [1]. O comportamento de um material submetido à fadiga é afetado por sua composição química e sua microestrutura, como o tamanho dos grãos, inclusões e segregações no material, além dos efeitos do processamento térmico e mecânico aplicado ao material. Em dimensões microscópicas, tem-se o movimento de discordâncias

(Recebido em 07/04/2011; Texto final em 16/09/2011). e os diferentes mecanismos de multiplicação e interação destas com outros defeitos cristalinos. O movimento de discordâncias nos planos de deslizamentos promove a formação de bandas de deslizamento, com surgimento de extrusões e intrusões na superfície do material e eventual nucleação e subsequente propagação de trincas. Em dimensões macroscópicas temse a geometria, as dimensões do componente, a presença de entalhes e as condições de acabamento superficial. Estes fatores microscópicos e macroscópicos se unem para determinar a resistência do componente à fadiga.

Uma das maneiras de se estudar a degradação por fadiga é através de ensaios que apresentam ciclos típicos para cada situação. Alguns destes ciclos são de tensões regulares e outros de tensões irregulares ou aleatórias. Na Figura 1 é apresentado o caso de tensões regulares (ou de amplitude constante). Nessa figura, tem-se a variação da tensão ao longo do tempo onde se distingue a tensão máxima $\left(\sigma_{\max }\right)$ e mínima $\left(\sigma_{\min }\right)$ que 
correspondem, respectivamente, aos picos máximos e mínimos dos ciclos de tensão.

A amplitude da tensão alternada $\left(\sigma_{a}\right)$ é definida por:

$$
\sigma_{a}=\frac{\sigma_{\max }-\sigma_{\min }}{2}
$$

A tensão média $\left(\sigma_{m}\right)$ é a média algébrica das tensões máxima e mínima no ciclo, ou seja:

$$
\sigma_{m}=\frac{\sigma_{\max }+\sigma_{\min }}{2}
$$

O intervalo de tensão cíclica (alternada), também chamado de variação da tensão, é representado por $\Delta \sigma$.

$$
\Delta \sigma=\sigma_{\max }-\sigma_{\min }
$$

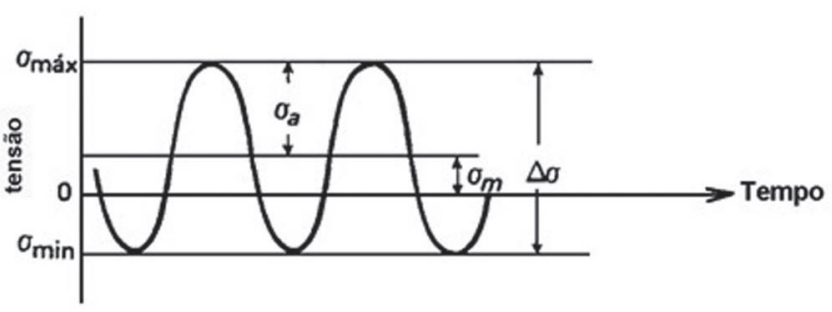

Figura 1. Parâmetros de ensaio de fadiga.

As tensões atuantes em um componente são obtidas por meio da análise experimental de tensões e/ou por modelos numéricos ou analíticos. Ao serem realizados experimentos para o estudo de fadiga, percebe-se que a variável resposta, tempo de falha das unidades sob teste, apresenta valores diferentes para um mesmo nível de tensão alternada aplicada. Na estatística, isto equivale a dizer que, para cada nível de tensão, os tempos de falha das unidades seguem certa distribuição de probabilidade [2]. O modelo de regressão (distribuição Log-normal) aplicado aos dados experimentais obtidos para o levantamento da curva S-N-P permite normalizar estes dados. A idéia geral deste método é que se podem encontrar modelos de regressão que descrevem o comportamento do tempo de falha das unidades por meio de duas componentes: uma componente determinística e outra probabilística. A componente probabilística do modelo determina a variabilidade inerente dos dados. Isto é feito ao se assumir uma distribuição de probabilidade para o tempo de falha do material sob teste (as distribuições mais utilizadas são a lognormal e a Weibull). Isto significa que, para cada nível de tensão, o tempo de falha do material segue uma mesma distribuição de probabilidade e o que faz diferir um nível de tensão do outro são os valores dos parâmetros desta distribuição.

A análise de fadiga para ser considerada válida e completa, precisa levar em consideração fatores que possam influenciar os resultados dos ensaios. Dentre os fatores que influenciam a vida de fadiga, podem-se destacar: condições superficiais, tensões residuais, tensões médias, tipos de carregamentos aplicados, freqüências de aplicações das cargas, condições do meio ambiente e a microestrutura do material $[3,4]$.

Tensões residuais são aquelas presentes num material ou componente estrutural, na ausência de cargas externas ou variações de temperatura. Tensões residuais são introduzidas no material como resultado de processos como soldagem que podem produzir deformação nas proximidades da superfície do material. Os efeitos das tensões residuais podem ser benéficos ou prejudiciais, dependendo, sobretudo da grandeza, sinal e distribuição das tensões em relação às cargas de serviço do componente ou da estrutura. Comumentemente, tensões residuais são prejudiciais e há muitos casos documentados nos quais estas tensões foram fatores predominantes para a falha por fadiga e outras falhas estruturais, quando as tensões de serviço foram superpostas às residuais já presentes na estrutura.

$\mathrm{O}$ processo de solda introduz tensões residuais devido à geometria resultante da fusão do material soldado e de seu resfriamento heterogêneo. Além da alteração microestrutural e da composição química do material na zona afetada pelo calor, introduzida pela soldagem, também se tem o efeito da descontinuidade dos passes e a formação de bolhas e vazios que podem contribuir para a nucleação de trincas, reduzindo a resistência à fadiga. $\mathrm{O}$ comportamento das tensões residuais em relação à resistência por fadiga é muito similar ao comportamento das tensões estáticas presentes na superfície do material. A tensão estática compressiva na superfície aumenta a resistência à fadiga, pois retarda o surgimento de trincas. Por outro lado, tensões residuais de tração reduzem a vida em fadiga [5]. Como tensões residuais podem ser de compressão ou de tração a importância de sua avaliação para se estudar a vida de fadiga de juntas soldadas se torna muito mais necessária quando se tem o caso de juntas soldadas de materiais dissimilares [6 -7].

Existem vários métodos para medir tensões residuais que podem ser classificados em não-destrutivos, semi-destrutivos e destrutivos. Os métodos não-destrutivos e semi-destrutivos são os mais interessantes por proporcionarem uma análise das tensões na peça em estudo nas condições reais de trabalho. Já os métodos destrutivos necessitam de corpo-de-prova extraído da peça a ser examinada. A técnica moderna mais amplamente usada para medições de tensões residuais é a "Blind-HoleDrilling Method", ou seja, técnica da usinagem do furo central ou simplesmente "Método do furo central". Este é um método semi-destrutivo, podendo ser em alguns casos considerado nãodestrutivo.

Neste método, após a instalação de sensores (rosetas especiais), Figura. 2(a), na superfície do componente, um pequeno e raso furo é usinado, no centro destas rosetas. Para as medições das deformações residuais utilizam-se rosetas adequadas para cada material, como na pratica da extensometria convencional. A colagem das rosetas à peça em estudo se faz utilizando-se adesivos à base de ciaanoacrilato. Depois da usinagem do furo, a mudança da deformação na vizinhança do furo é medida e as tensões residuais são calculadas Figura 2(b).

A eliminação destas tensões na superfície do furo muda o valor e a distribuição das tensões na vizinhança imediata deste, causando mudança nas distribuições de deformações locais na superfície de teste. Os dados de deformação dos três extensômetros são adquiridos, utilizando-se a Ponte de Wheatstone, após cada incremento de corte e são tratados segundo a Norma ASTM E 837[8]. Estes dados são transformados em deformação utilizando-se a Equação 4: 


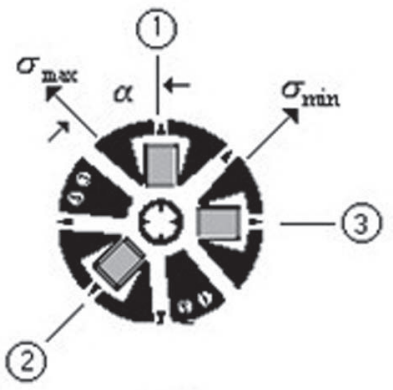

(a)

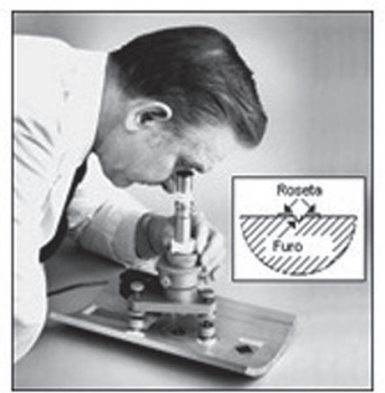

(b)
Figura 2. (a) Roseta típica para Tensão Residual. (b) Equipamento para centrar e usinar o furo [9].

$$
\varepsilon=\frac{4 \Delta V}{V K}
$$

Sendo: $\Delta V$ o sinal de saída da Ponte de Wheatstone, e V sua alimentação. K é o fator de sensibilidade de cada extensometro da roseta.

Após o cálculo das deformações o seguinte procedimento deve ser seguido:

a) Cálculo das deformações, para cada incremento de profundidade:

$$
\varepsilon_{3}+\varepsilon_{1} \quad \varepsilon_{3}-\varepsilon_{1} \quad \varepsilon_{3}+\varepsilon_{1}-2 \varepsilon_{2}
$$

b) Normalização dos valores obtidos, tomando como $100 \%$ os resultados para $\mathrm{z} / \mathrm{D}=0,4$, onde $\mathrm{z}$ é a profundidade final e D é o diâmetro característico da roseta instalada.

c) Verificação da uniformidade do campo de tensões obtido (Figura 3).

d) Se o campo das tensões for uniforme os valores obtidos em "b", deverão cair dentro das faixas estabelecidas para $\left(\varepsilon_{3}+\varepsilon_{1}\right) \%$ e a maior das duas $\left(\varepsilon_{3}-\varepsilon_{1}\right) \%$ ou ( $\left.\varepsilon_{3}+\varepsilon_{1}-2 \varepsilon_{2}\right) \%$.

e) Cálculo das tensões utilizando as Equações 6 a 9:

$$
\begin{aligned}
\sigma_{\max } & =\frac{\varepsilon_{1}+\varepsilon_{3}}{4 \bar{A}}-\frac{1}{4 \bar{B}} \sqrt{\left(\varepsilon_{3}-\varepsilon_{1}\right)^{2}+\left(\varepsilon_{3}+\varepsilon_{1}-2 \varepsilon_{2}\right)^{2}} \\
\sigma_{\min } & =\frac{\varepsilon_{1}+\varepsilon_{3}}{4 \bar{A}}+\frac{1}{4 \bar{B}} \sqrt{\left(\varepsilon_{3}-\varepsilon_{1}\right)^{2}+\left(\varepsilon_{3}+\varepsilon_{1}-2 \varepsilon_{2}\right)^{2}} \\
\bar{A} & =-\frac{1+\mu}{2 E} \bar{a} \\
\bar{B} & =-\frac{1}{2 E} \bar{b}
\end{aligned}
$$

Sendo: $\mu$ o coeficiente de Poisson do material sob teste;

\begin{tabular}{|c|c|c|c|c|c|c|c|c|c|c|}
\hline \multirow{3}{*}{$\mathbf{x}=\mathbf{z} / \mathbf{D}$} & \multicolumn{5}{|c|}{$\mathbf{y}=\bar{a}$} & \multicolumn{5}{|c|}{$\mathbf{y}=\bar{b}$} \\
\hline & \multicolumn{5}{|c|}{ Diâmetro do Furo $\mathrm{D}_{0} / \mathrm{D}$} & \multicolumn{5}{|c|}{ Diâmetro do Furo $\mathrm{D}_{0} / \mathrm{D}$} \\
\hline & $\mathbf{0 , 3 0}$ & 0,35 & 0,40 & 0,45 & $\mathbf{0 , 5 0}$ & $\mathbf{0 , 3 0}$ & 0,35 & 0,40 & 0,45 & $\mathbf{0 , 5 0}$ \\
\hline 0 & 0 & 0 & 0 & 0 & 0 & 0 & 0 & 0 & 0 & 0 \\
\hline 0,05 & 0,027 & 0,037 & 0,049 & 0,063 & 0,08 & 0,051 & 0,069 & 0,09 & 0,113 & 0,14 \\
\hline 0,1 & 0,059 & 0,081 & 0,108 & 0,138 & 0,176 & 0,118 & 0,159 & 0,206 & 0,255 & 0,317 \\
\hline 0,15 & 0,085 & 0,115 & 0,151 & 0,192 & 0,238 & 0,18 & 0,239 & 0,305 & 0,375 & 0,453 \\
\hline 0,2 & 0,101 & 0,137 & 0,177 & 0,223 & 0,273 & 0,227 & 0,299 & 0,377 & 0,459 & 0,545 \\
\hline 0,25 & 0,11 & 0,147 & 0,19 & 0,238 & 0,288 & 0,259 & 0,339 & 0,425 & 0,513 & 0,603 \\
\hline 0,3 & 0,113 & 0,151 & 0,195 & 0,243 & 0,293 & 0,279 & 0,364 & 0,454 & 0,546 & 0,638 \\
\hline 0,35 & 0,113 & 0,151 & 0,195 & 0,242 & 0,292 & 0,292 & 0,379 & 0,472 & 0,566 & 0,657 \\
\hline 0,4 & 0,11 & 0,149 & 0,192 & 0,239 & 0,289 & 0,297 & 0,387 & 0,482 & 0,576 & 0,668 \\
\hline Passante & 0,09 & 0,122 & 0,16 & 0,203 & 0,249 & 0,288 , & 0,377 & 0,47 & 0,562 & 0,651 \\
\hline
\end{tabular}
E o módulo de Elasticidade do material sob teste; $\bar{a}$ e $\bar{b}$ os coeficientes de alívio obtidos pela Tabela 1.

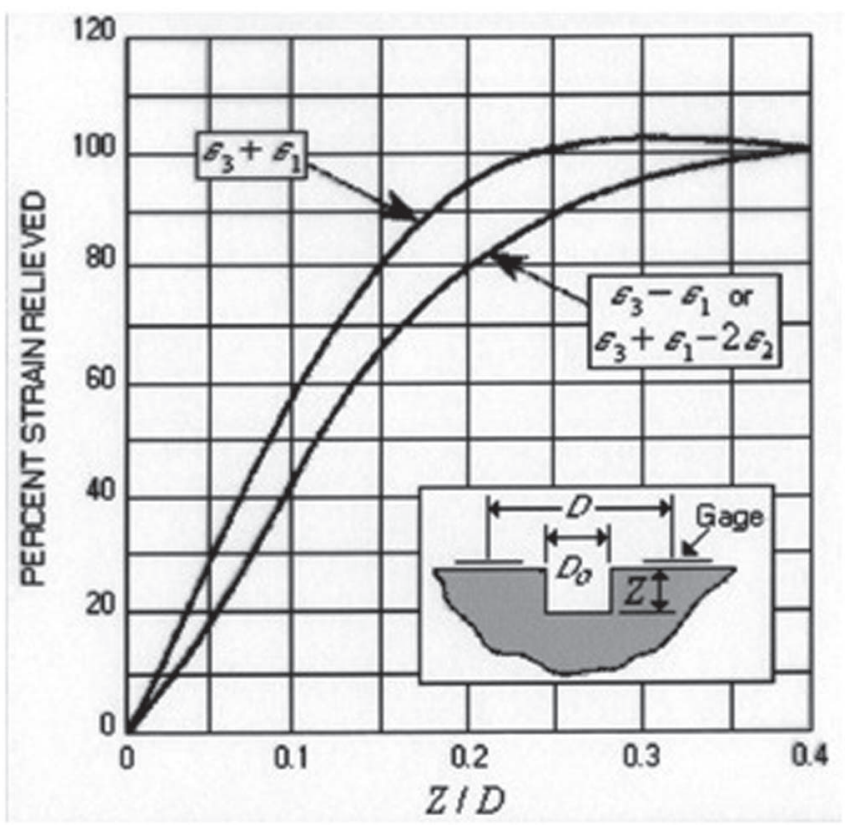

Figura 3. Campo de Tensões Residuais Uniformes Padrão.

Tabela 1. Coeficientes de alívio. 
Se o campo das tensões não for uniforme as tensões em cada incremento são chamadas de Tensões Residuais Principais Uniformes Equivalentes (TRPUE).

As TRPUE são aquelas grandezas de tensão as quais, se uniformemente distribuídas, produziriam a mesma deformação aliviada total, para cada incremento, como medido durante a usinagem dos furos.

Quando a tensão residual é muito próxima do limite de escoamento, a concentração de tensão devida ao furo pode introduzir escoamento localizado na área.

Várias pesquisas relatam que para tensões residuais menores que $70 \%$ do limite de escoamento que erros provocados pelo escoamento localizado são desprezíveis.

Neste trabalho são determinadas tensões residuais nas soldas dissimilares, apresentadas curvas S-N-P que relacionam tensão com o número de ciclos e a probabilidade de falha, para 4 metais: cobre eletrolítico, aço inoxidável AISI 304, aço inoxidável AISI 316L e aço carbono A36 que foram posteriormente soldados entre si.

\section{Procedimento Experimental}

\subsection{Materiais}

Os materiais utilizados nos ensaios de fadiga foram confeccionados de chapas de aço inoxidável AISI 304, aço carbono A36, cobre eletrolítico e aço inoxidável AISI 316L. $\mathrm{Na}$ soldagem de aço inoxidável AISI 304 com aço carbono A36 foi utilizado aço inoxidável AISI 316L como metal de adição. Na soldagem do aço inoxidável AISI 304 com cobre foi utilizado o próprio cobre como metal de adição. Esta escolha foi feita para garantir uma boa diluição do cobre com o cobre e consequentemente com o aço inoxidável [10].
Os corpos de prova foram produzidos a partir de chapas soldadas conforme o desenho esquemático apresentado na Figura 4.

Para a medição das tensões residuais provocadas pelo processo de soldagem foram utilizadas rosetas FRS-2-11 para o aço carbono A36 e rosetas FRS-2-17 para os aços inoxidáveis e para o cobre. Estas rosetas têm o coeficiente de dilatação do seu elemento sensor adequadas à utilização em cada um dos metais estudados. As rosetas foram coladas nas chapas soldadas utilizando-se adesivos à base de cianoacrilato. As rosetas e o adesivo utilizado $(\mathrm{CN})$ são de fabricação TML (Tokyo Sokki Kenkyujo CO, Ltd).

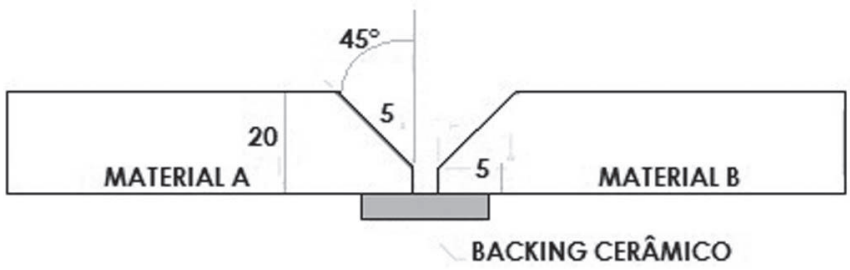

Figura 4. Desenho esquemático do corpo de prova para soldagem.

\subsection{Corpos-de-prova}

Para os ensaios de fadiga flexo rotativas foram utilizados os corpos de prova com a geometria apresentada na Figura 5 (a). A verificação da uniformidade de aplicação das tensões ao longo da região de ensaios foi realizada por meio de um corpode-prova instrumentado com 3 extensômetros elétricos, como mostrado na Figura 5(b).

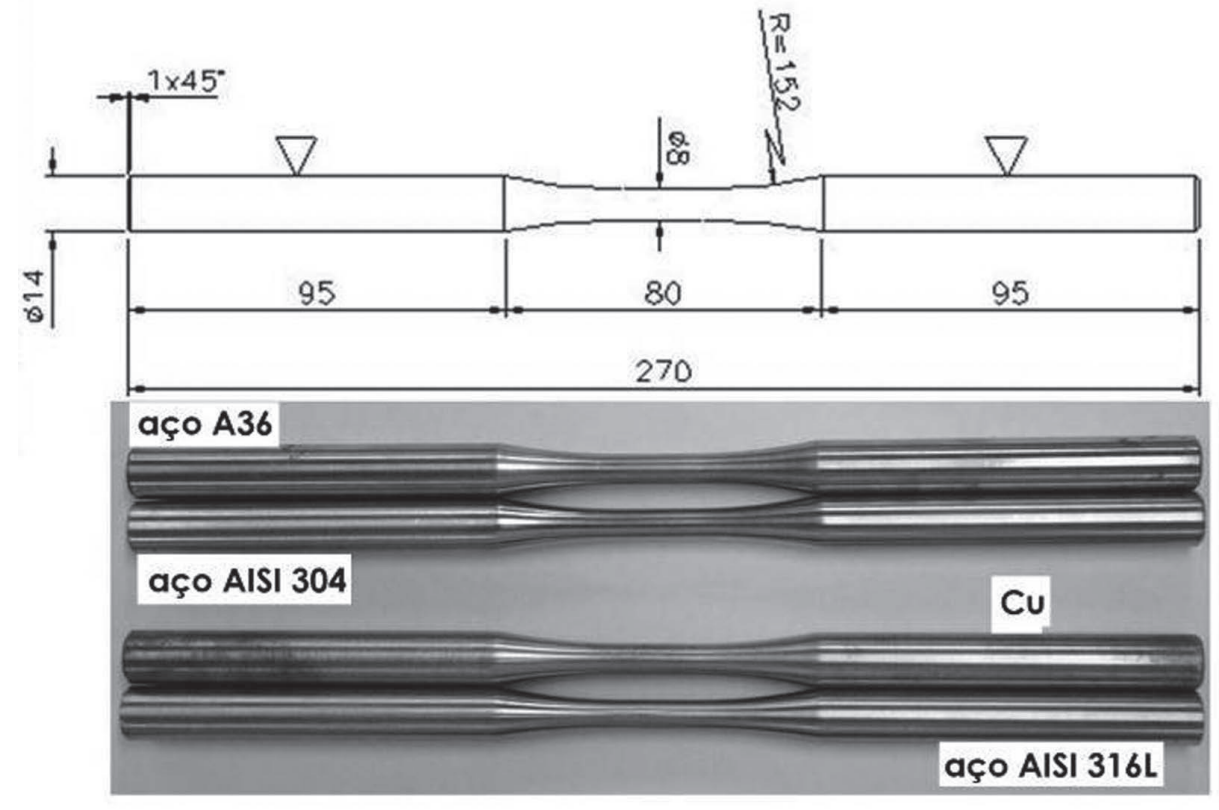

(a)

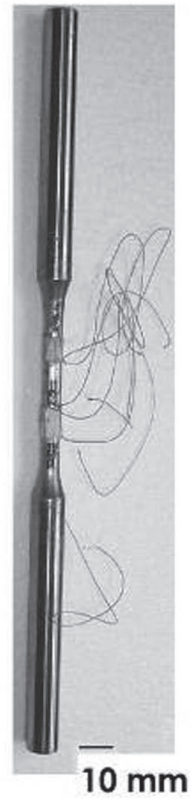

(b)

Figura 5. (a) Corpo-de-prova utilizado para os ensaios de fadiga. (b) Corpo-de-prova instrumentado. 


\subsection{Equipamentos e métodos utilizados}

Para a confecção das soldas em materiais dissimilares foram utilizadas as máquinas de soldagem MIG/MAG Smashweld 350. Para a realização da solda dissimilar cobre/aço inoxidável 304 utilizou-se como metal de adição o cobre. $\mathrm{O}$ gás utilizado foi o Argônio comercial com uma vazão de $16 \mathrm{l} / \mathrm{min}$. A velocidade do arame foi de $7 \mathrm{~m} / \mathrm{min}$ com stick-out de 25 a $30 \mathrm{~mm}$. Foram realizados 6 (seis) passes de soldagem cujos parâmetros são apresentados na Tabela 2. A chapa de cobre foi pré-aquecida à temperatura de aproximadamente $250^{\circ} \mathrm{C}$ e mantida durante a soldagem em $300^{\circ} \mathrm{C}$.

Tabela 2. Parâmetros de soldagem utilizados na soldagem da chapa de cobre com a chapa de aço AISI 304 com cobre como metal de adição.

\begin{tabular}{c|c|c|c}
\hline Passe & Corrente (A) & Tensão (V) & Tempo (s) \\
\hline 1 & 200 & 20,0 & 52 \\
2 & 220 & 20,0 & 54 \\
3 & 224 & 20,0 & 47 \\
4 & 220 & 20,0 & 51 \\
5 & 240 & 22,8 & 50 \\
6 & 240 & 22,8 & 60 \\
\hline
\end{tabular}

Tabela 3. Parâmetros de soldagem utilizados na soldagem da chapa de aço carbono A36 com aço AISI 304 utilizou-se como metal de adição o AISI 316L.

\begin{tabular}{c|c|c|c}
\hline Passe & Corrente (A) & Tensão (V) & Tempo (s) \\
\hline 1 & 156 & 21 & 82 \\
2 & 148 & 21 & 55 \\
3 & 152 & 21 & 52 \\
4 & 152 & 21 & 54 \\
5 & 144 & 23 & 62 \\
6 & 144 & 21 & 50 \\
7 & 140 & 21 & 52 \\
8 & 156 & 21 & 49 \\
\hline
\end{tabular}

Para a realização da solda dissimilar aço carbono A36 com aço inoxidável AISI 304 utilizou-se como metal de adição o aço inoxidável AISI 316 L [9]. O gás utilizado foi o Argônio comercial com uma vazão de $23 \mathrm{l} / \mathrm{min}$. A velocidade do arame foi de $6 \mathrm{~m} / \mathrm{min}$ com o stick-out de $25 \mathrm{~mm}$. Foram realizados 8 (oito) passes cujos parâmetros são apresentados na Tabela 2. A chapa de aço carbono A36 foi aquecida entre 80 a $100^{\circ} \mathrm{C}$ e a temperatura do conjunto não excedeu a $200^{\circ} \mathrm{C}$. Entre passes a temperatura não foi inferior a $100^{\circ} \mathrm{C}$.

Como o objetivo do trabalho não foi estudar os procedimentos de soldagem, não se preocupou com o número de passes utilizados em cada chapa soldada. Desta forma o número de passes foi diferente nas duas soldagens. Considerando um rendimento de $90 \%$, o aporte térmico da soldagem de cobre com inoxidável AISI 304 foi de $917 \mathrm{~J} / \mathrm{mm}$ e da soldagem do aço carbono A36 com o aço Inoxidável AISI 304, o aporte térmico foi de $695 \mathrm{~J} / \mathrm{mm}$.

As tensões residuais foram medidas nas chapas após a soldagem utilizando o Sistema de medição de tensões residuais pelo método do furo central marca Vishay modelo RS-200, mostrado na Figura 6. As variações das resistências elétricas foram medidas utilizando- se um multímetro digital marca Agilent, modelo 34401A.

Foram realizadas medidas de tensões residuais em 24 pontos na chapa soldada de aço inoxidável AISI 304 com cobre e na chapa soldada de aço inoxidável AISI 304 com aço carbono A36. Seis rosetas foram coladas na raiz da solda e dezoito rosetas no topo. Na Figura 7 apresenta-se uma foto com as posições (P1 a $\mathrm{P} 12)$ de cada roseta (R1 a R24).

Para a medição das deformações residuais provocadas pelo processo de soldagem foram utilizadas rosetas FRS-2-11 indicadas para uso em aço carbono e FRS-2-17 para uso em aço inoxidável e cobre. As deformações residuais foram medidas utilizando-se o procedimento interno do Laboratório de Análise Experimental de Tensões do CDTN, PO LATV 2. A furação no centro das rosetas para se obter o alívio das tensões foi em passos de $0,209 \mathrm{~mm}$, até uma profundidade de $Z=1,981 \mathrm{~mm}$. Em cada passo foram medidas as variações das resistências. A temperatura de ensaio foi de $25^{\circ} \mathrm{C}$.

Para o ensaio de fadiga optou-se pelo ensaio por flexão rotativa, que é um método simples de determinação das propriedades de fadiga, com tensão média nula. Na Tabela 4 são apresentados o número de corpos de prova e o valor das tensões escolhidas para o ensaio.

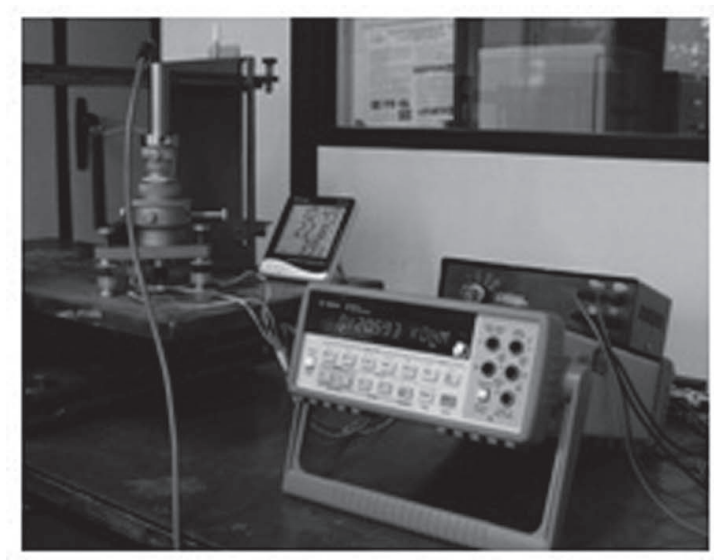

(a)

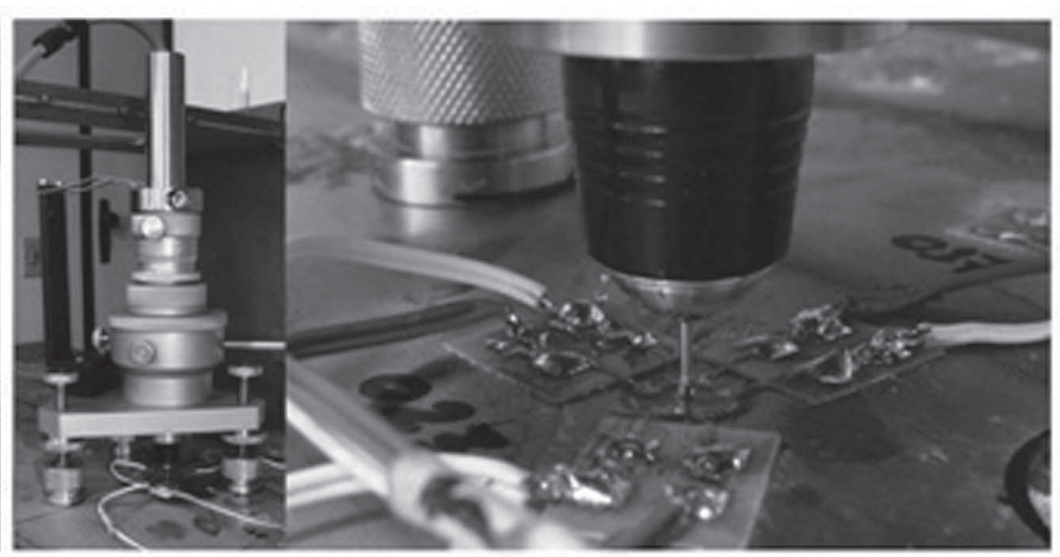

(b)

Figura 6. (a) Sistema de medição de tensões residuais pelo método do furo central. (b) Detalhe da execução de uma furação no centro da roseta. 


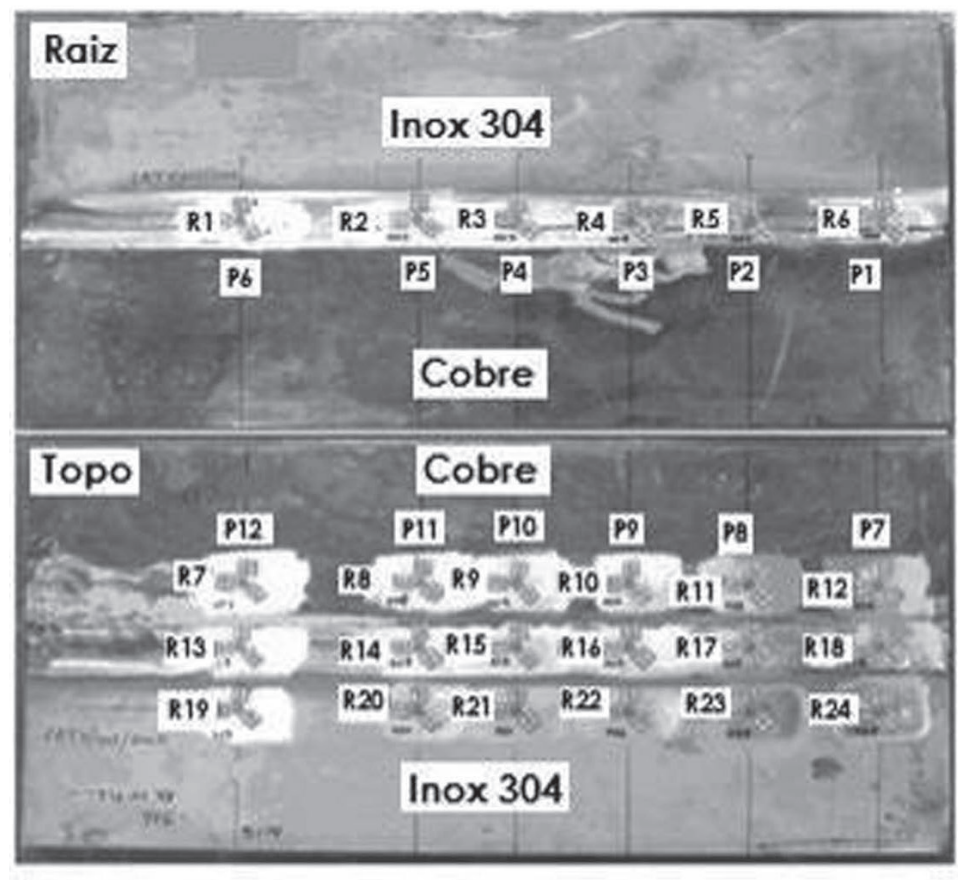

(a)

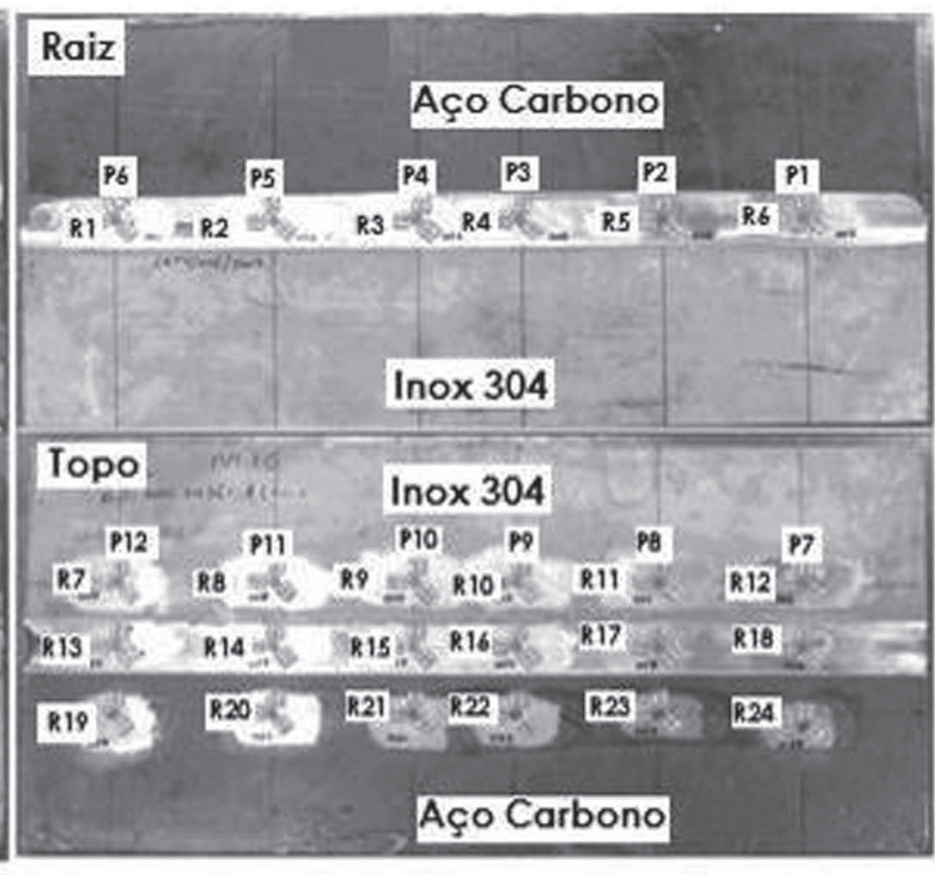

(b)

Figura 7. Pontos de medição das tensões residuais na (a) Chapa de aço AISI 304 e cobre (b) chapa de aço AISI 304 e aço carbono A36.

Tabela 4. Número de corpos de prova ensaiados para cada nível de tensão.

\begin{tabular}{|c|c|c|c|c|c|c|c|c|c|c|c|c|c|c|c|}
\hline \multirow[b]{2}{*}{ Tensão (MPa) } & \multicolumn{4}{|c|}{ A36 } & \multicolumn{3}{|c|}{ Cobre } & \multicolumn{4}{|c|}{ AISI 304} & \multicolumn{4}{|c|}{ AISI 316L } \\
\hline & 262 & 239 & 217 & 197 & 135 & 113 & 77,5 & 278 & 271 & 251 & 245 & 340 & 315 & 265 & 240 \\
\hline$N^{o}$ de $C^{\prime}$ 's & 3 & 5 & 7 & 7 & 2 & 3 & 5 & 3 & 3 & 4 & 6 & 2 & 2 & 4 & 6 \\
\hline
\end{tabular}

Tabela 5. Verificação do ajuste do modelo de regressão.

\begin{tabular}{c|l|c|c|c}
\hline Material & \multicolumn{1}{|c|}{ Intercepto } & $\begin{array}{c}\text { Coeficiente } \\
\text { da variável } \\
\text { preditora, } \beta_{1}\end{array}$ & $\begin{array}{c}\text { Parâmetro de escala } \\
\text { da distribuição } \\
\text { Log-normal, } \sigma\end{array}$ & $\begin{array}{c}\text { Modelo onde T tem uma distribuição Log-normal } \\
\text { com parâmetros } \mu(x)=\beta_{0}+\beta_{1} x \\
\text { (que depende do valor de } x=\text { nível de tensão) }\end{array}$ \\
\hline Aço A36 & $\mathbf{2 3 , 8 1 4 3}$ & $-0,0462598$ & 0,471860 & $Y=\ln (T)=23,8143-0,0462598 x+0,471860 \varepsilon$ \\
\hline Aço 316L & $\mathbf{2 3 , 0 7 6 0}$ & $-0,0319787$ & 0,557148 & $Y=\ln (T)=23,0760-0,0319787 x+0,4557148 \varepsilon$ \\
\hline Aço 304 & $\mathbf{4 8 , 4 8 4 8}$ & $-0,135217$ & 0,261331 & $Y=\ln (T)=48,4848-0,135217 x+0,261331 \varepsilon$ \\
\hline Cobre & $\mathbf{1 9 , 9 5 0 0}$ & $-0,0708043$ & 0,282667 & $Y=\ln (T)=19,9500-0,0708043 x+0,282667 \varepsilon$ \\
\hline
\end{tabular}




\section{Resultados e Discussão}

Nos ensaios para a determinação das curvas S-N, foram utilizados os níveis de tensões alternadas mostrados na Tabela 3. As curvas são apresentadas na Figura 9. O número de ciclos utilizado como vida infinita foi de $2,0 \times 10^{6}$ ciclos.

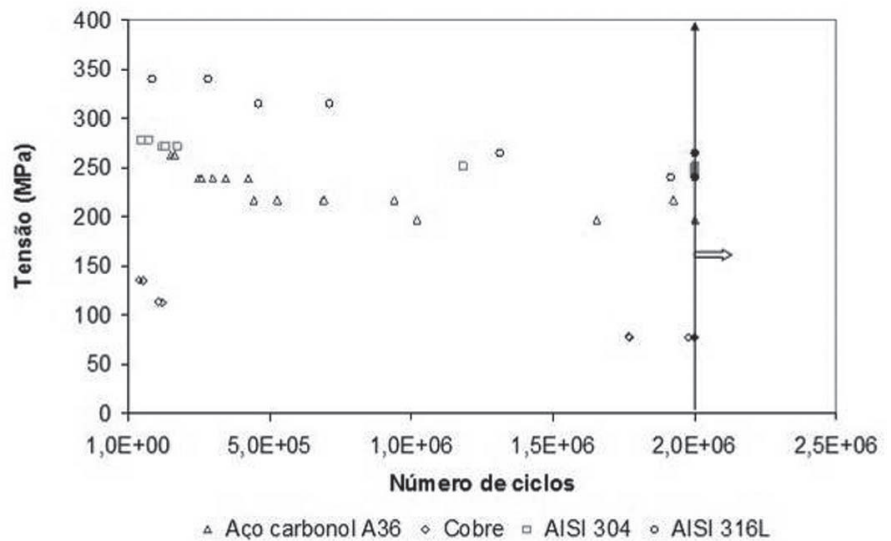

Figura 8. Curva S-N para os materiais testados: aço carbono A36, aço AISI 316L, aço AISI 304 e cobre.

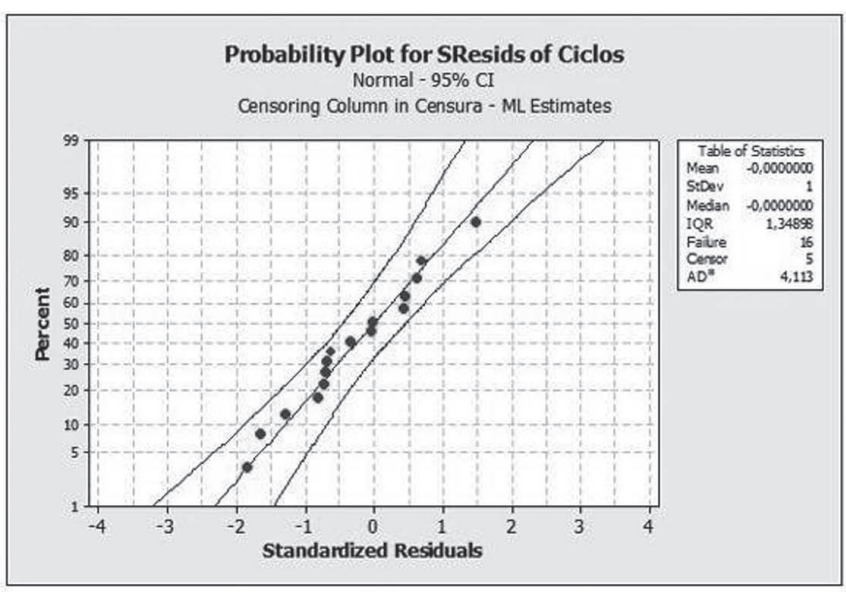

(a)

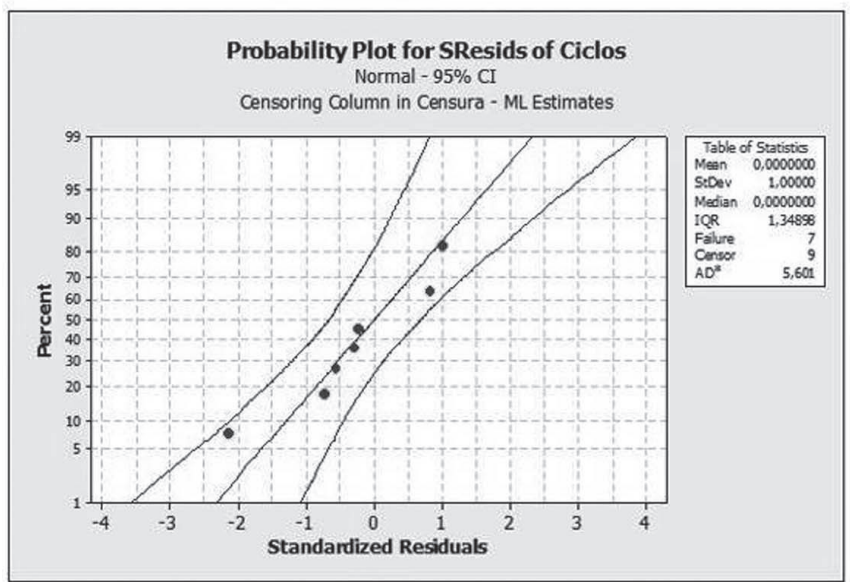

(c)
A verificação do ajuste do modelo de regressão foi feita para os corpos de prova ensaiados utilizando a distribuição Lognormal. A estimação dos parâmetros deste modelo e a verificação dos mesmos foram feitas utilizando-se o software MINITAB [11] na versão 15. Os resultados estão apresentados na Tabela 5. Os modelos ajustados mostraram-se adequados, pois os pontos na Figura 9, que representam os resíduos de modelo (valores ajustados - valores observados), aproximam-se de uma reta. Todos os pontos estão situados dentro do intervalo de $95 \%$ de confiança.

Na Figura 10 apresentam-se as curvas S-N-P obtidas com os resultados dos ensaios de fadiga flexo-rotativos.

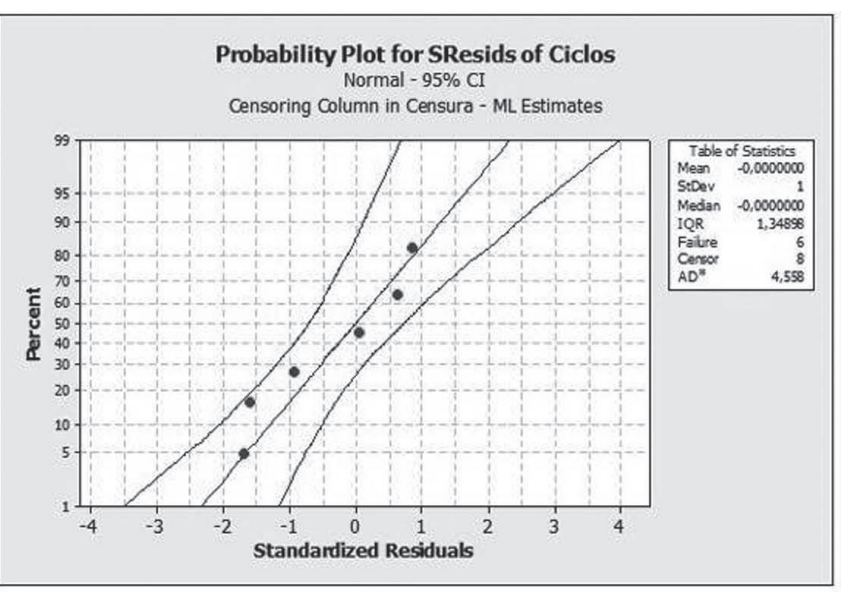

(b)

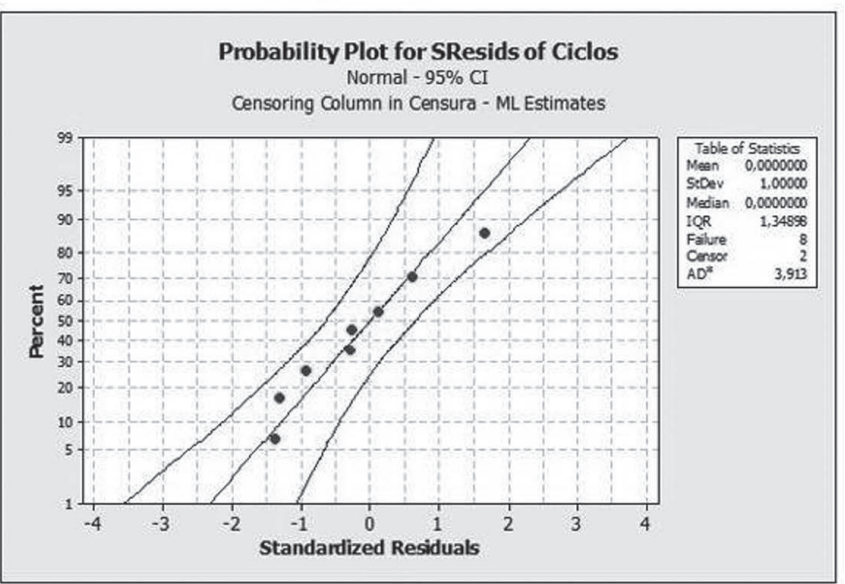

(d)

Figura 9. Gráficos de probabilidades para resíduos padronizados de ciclos (a) aço carbono A36 (b) aço AISI 316L (c) aço AISI 304 e (d) cobre. 
Curvas S-N-P $\mathbf{5 0 \%}$ probabilidade de falha

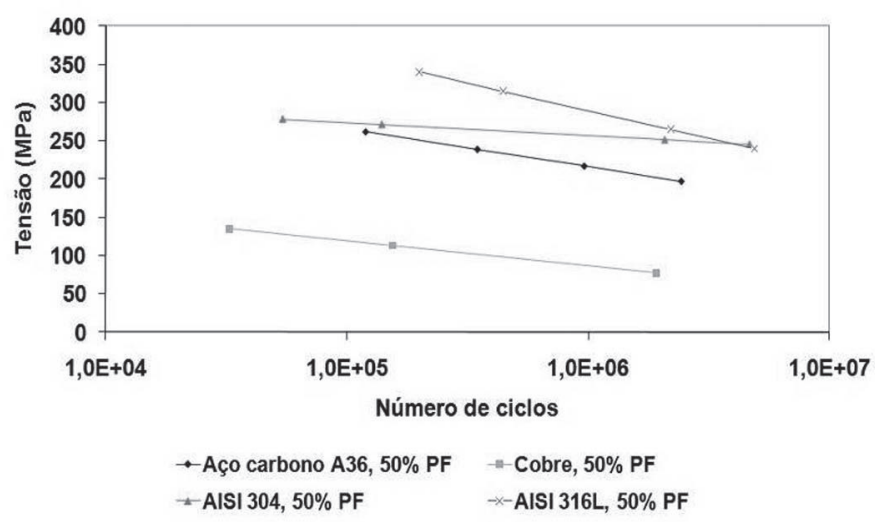

Figura 10. Curvas SNP 50\% de probabilidade de falha.
Para estimar o Limite de Resistência à Fadiga dos materiais estudados, utilizou-se a função de confiabilidade da distribuição Log-normal e o cálculo do inverso, que é a obtenção de $x_{0}$ a partir da Equação 10.

$\hat{R}(T)=\Phi\left\{-\left[\frac{\ln (t)-\hat{\beta}_{0}-\hat{\beta}_{1} x_{0}}{\hat{\Gamma}}\right]\right\}$

Sendo: $\Phi$ o percentil da distribuição normal padrão, $\hat{\beta}_{0}, \hat{\beta}_{1}$ , e $\hat{\Gamma}$ os parâmetros estimados pelo modelo, $t$ o tempo de vida de interesse, neste caso $2 \times 10^{6}$ ciclos e $x_{0}$ é o nível de tensão.

$\mathrm{O}$ Limite de Resistência à Fadiga é o valor $x_{0}$ para o qual se tem $R(T)=50 \%$, ou seja, a probabilidade de falha dos corposde-prova após 2.000 .000 ciclos é de $50 \%$. Na Tabela 6 são apresentados os resultados para os diferentes materiais.

Tabela 6. Limites de resistência à fadiga dos materiais testados.

\begin{tabular}{c|c|c}
\hline Material & Equação & Valor $\boldsymbol{x}_{\boldsymbol{o}}$ (MPa) \\
\hline Aço carbono A36 & $x_{0}=\frac{1}{\beta_{1}}\left[\theta^{-1} \sigma+\ln (t)-\beta_{0}\right]=\frac{1}{-0,0462598}[0 * 0,471860+\ln (2000000)-23,8143]$ & 201 \\
\hline Aço inoxidável 316L & $x_{0}=\frac{1}{\beta_{1}}\left[\theta^{-1} \sigma+\ln (t)-\beta_{0}\right]=\frac{1}{-0,0319787}[0 * 0,557148+\ln (2000000)-23,076]$ & 268 \\
\hline Aço inoxidável 304 & $x_{0}=\frac{1}{\beta_{1}}\left[\theta^{-1} \sigma+\ln (t)-\beta_{0}\right]=\frac{1}{-0,135217}[0 * 0,261331+\ln (2000000)-48,4848]$ & 251 \\
\hline Cobre & $x_{0}=\frac{1}{\beta_{1}}\left[\theta^{-1} \sigma+\ln (t)-\beta_{0}\right]=\frac{1}{-0,0708043}[0 * 0,282667+\ln (2000000)-19,95]$ & 77 \\
\hline
\end{tabular}

Na Figura 11 observa-se um ligeiro aumento no Limite de Resistência à Fadiga (LRF) para os aços estudados. Para o cobre o LRF é bem menor.

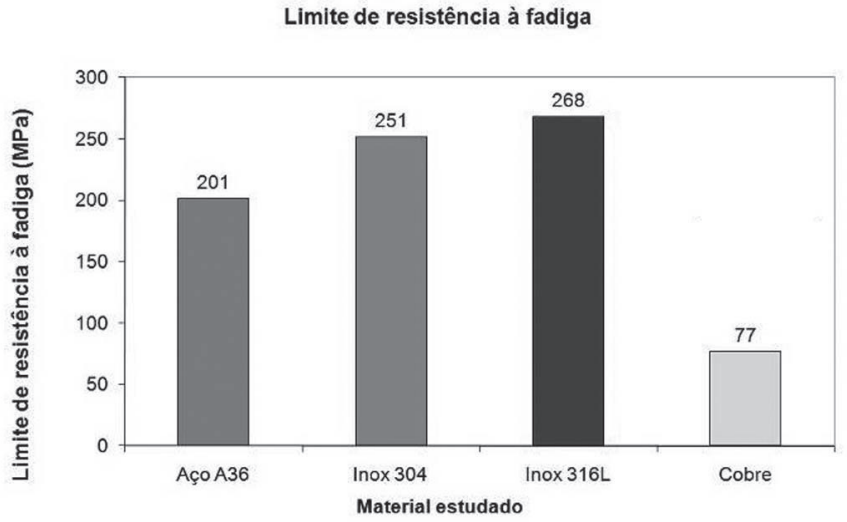

Figura 11. Valores determinados para os Limites de Resistência à Fadiga.

Na Figura 12 estão apresentados os resultados das medições das tensões residuais obtidos para a solda entre a chapa de cobre e a chapa de aço inoxidável AISI 304, materiais dissimilares.

Os valores obtidos nos cálculos das tensões residuais utilizando-se a norma ASTM E 837-01 [8] determinaram um campo de tensão não uniforme. Após esta análise calculou-se as
Tensões Residuais Principais Uniformes Equivalentes (TRPUE) [9].

As TRPUE são aquelas grandezas de tensão as quais, se uniformemente distribuídas, produziriam a mesma deformação aliviada total, para cada incremento, como medido durante a usinagem do furo central.

Devido às tensões residuais serem tratadas como tensões provenientes de solicitações externas, apresentam-se também as tensões equivalentes determinadas pelo Critério de Tresca.

Observa-se para a chapa de cobre, que com exceção da posição 9, as tensões residuais medidas ultrapassam a 70\% do limite de escoamento do cobre. Isto indica que o método de medição das tensões residuais, método do furo central, não se aplica [9]. Os valores obtidos indicam apenas que a tensão residual nos pontos estudados é muito alta. Observa-se também que as tensões medidas, com exceção da posição 9 são de tração. Para a chapa de aço inoxidável AISI 304, os valores medidos para as tensões residuais estão abaixo de $70 \%$ do limite de escoamento do material. Não existe diferença apreciável entre os valores das tensões residuais para o início do cordão de solda e o final do mesmo. As tensões residuais são em sua maioria de tração. Observa-se para o cordão de solda no topo da chapa, que o métode medição das tensões residuais não se aplica às posições 10 e 12. Isto esta indicando que a proximidade da chapa de aço inoxidável AISI 304 faz o cordão de solda, que é também de cobre, ter níveis de tensões residuais menores que a chapa de cobre propriamente dita. Observam-se tensões 
Tanius Rodrigues Mansur, Nelson do N. Atanazio Filho, Paulo de Tarso Vida Gomes, Emerson Giovani Rabello, Luiz Leite da Silva, Geraldo Antônio Scoralick, Mariana Coelho de Vasconcelos Santos, Alexandre Queiroz Bracarense
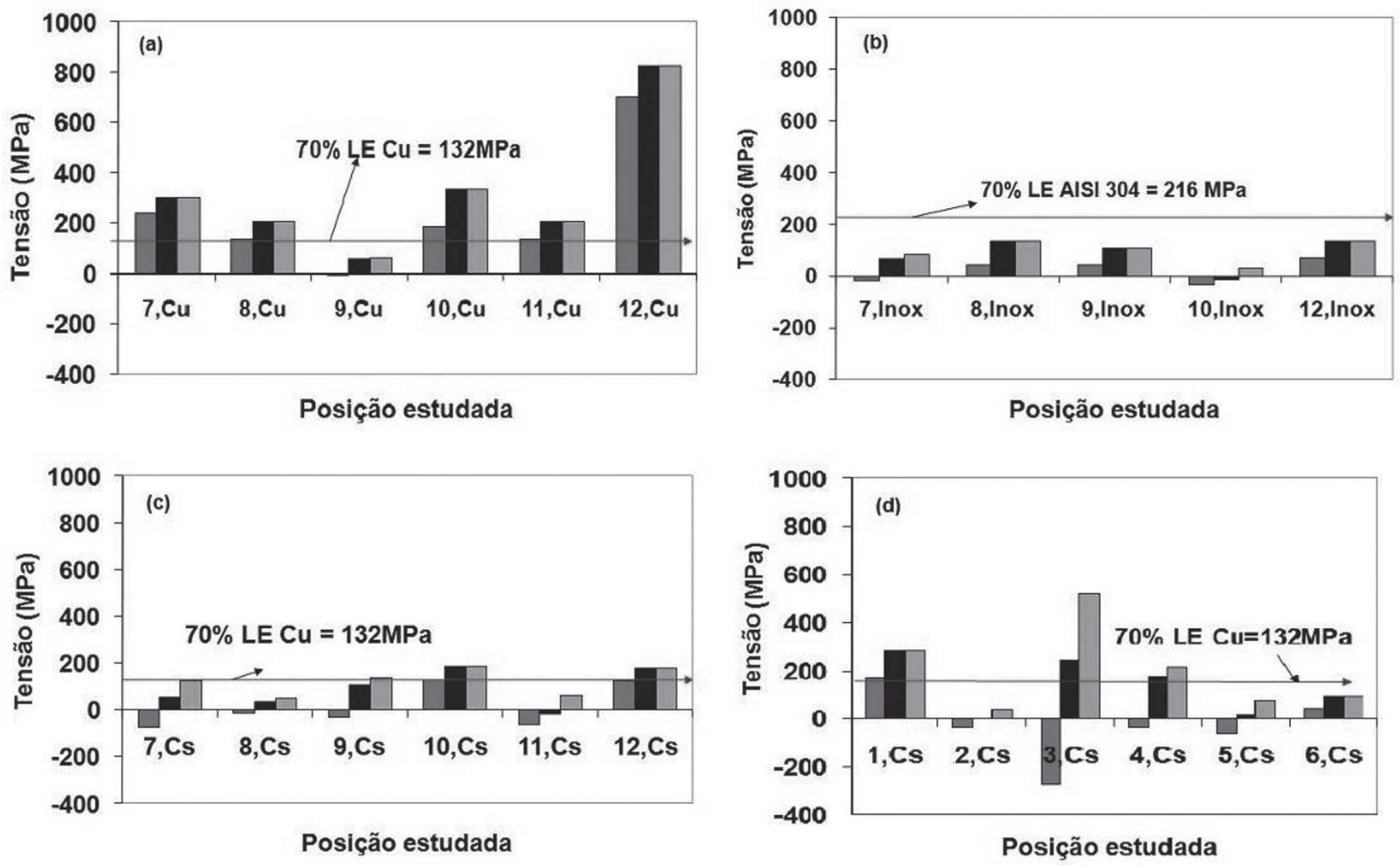

घ Tensão residual uniforme equivalente, mínima

- Tensão residual uniforme equivalente, máxima

$\square$ critèrio de Tresca

Figura 12. Tensão residual uniforme equivalente no topo da chapa de cobre (a), da chapa de aço AISI 304(b) e do cordão de solda (c). Em (d) da raiz do cordão de solda.
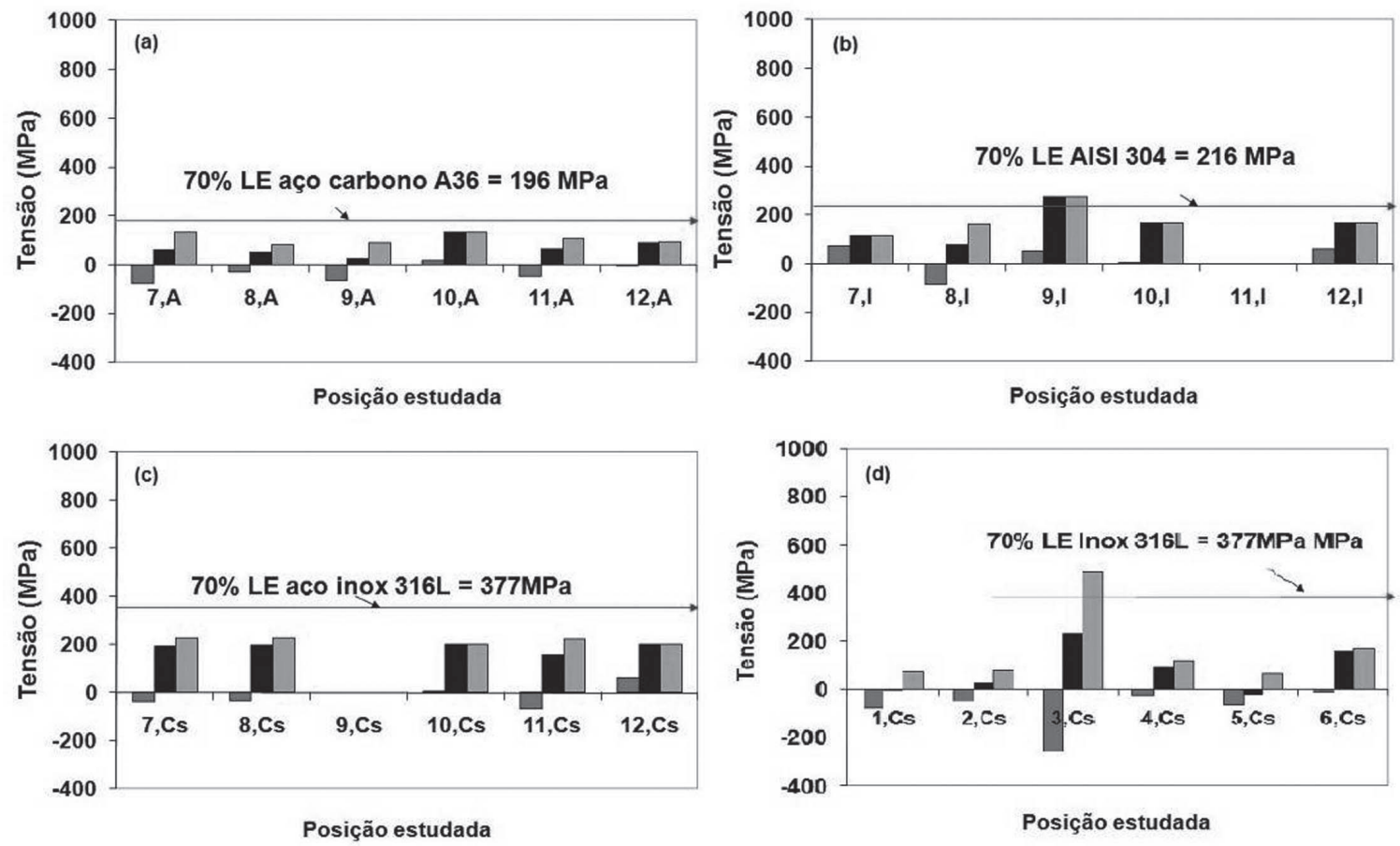

घ Tensão residual uniforme equivalente, minima

- Tensão residual uniforme equivalente, máxima

$\square$ Critério de Tresca

Figura 13. Tensão residual uniforme equivalente no topo da chapa de Aço carbono A36 (a), da chapa de aço AISI 304 (b) e do cordão de solda (c). Em (d) da raiz do cordão de solda. 
de compressão para o cordão de solda. Em relação à raiz do cordão de solda, observam-se tensões residuais de compressão para 5 das 6 posições medidas. Dos 6 pontos estudados, para 3 deles o método de medição das tensões residuais não se aplica. Comparando-se as tensões residuais medidas para o cordão de solda (a posição 1 na raiz da solda é diametralmente oposta à posição 7 no topo, a posição 2 à posição 8 e assim por diante), observam-se valores maiores para a raiz da solda.

Os resultados das medições das tensões residuais obtidos para a solda dissimilar aço carbono A36 e aço inoxidável AISI 304 estão mostrados na Figura 13.

Observa-se que o método de medição das tensões residuais se aplica para todas as posições estudadas no aço carbono A36. Com exceção da posição 10 , todos os pontos apresentam tensões de compressão. Analisando as tensões sob a ótica do Critério de Tresca observa-se que as tensões apresentam pouca variação na direção do cordão de solda: do início para o final (posição 7 para a posição 12). Para a chapa AISI 304 apenas uma posição de medição apresenta tensão de compressão e para a posição 90 método de medição não se aplica. As tensões residuais medidas, levando-se em consideração o Critério de Tresca, são maiores para chapa de aço inoxidável AISI 304 que para a chapa de aço carbono A36. Em relação o cordão de solda feito com o aço inoxidável AISI 316L as tensões residuais medidas são menores que $60 \%$ do limite de escoamento do material. Portanto, o método de medição das tensões residuais é válido para todas as posições estudadas. Com exceção das posições 10 e 12 todas as posições apresentam tensões residuais de compressão. Em relação ao Critério de Tresca, os maiores valores obtidos para as tensões residuais são aço inoxidável AISI 316L (cordão de solda), aço inoxidável AISI 304 e depois aço carbono A36. Para a raiz da solda todas as posições estudadas apresentam tensões de compressão e para uma posição o método de medição não se aplica. Em relação ao Critério de Tresca os maiores valores medidos para o cordão de solda são para as posições no topo.

As maiores tensões residuais utilizando-se o Critério de Tresca (Figura 14), para o topo dos cordões de solda ocorrem para a chapa aço carbono A36 soldada com o aço inoxidável AISI 306. Este cordão de solda foi feito com aço AISI 316L. Para as raízes dos cordões de solda em 4 posições estudadas, as tensões residuais desenvolvidas no cordão de cobre são maiores

Critério de Tresca para os cordões de solda

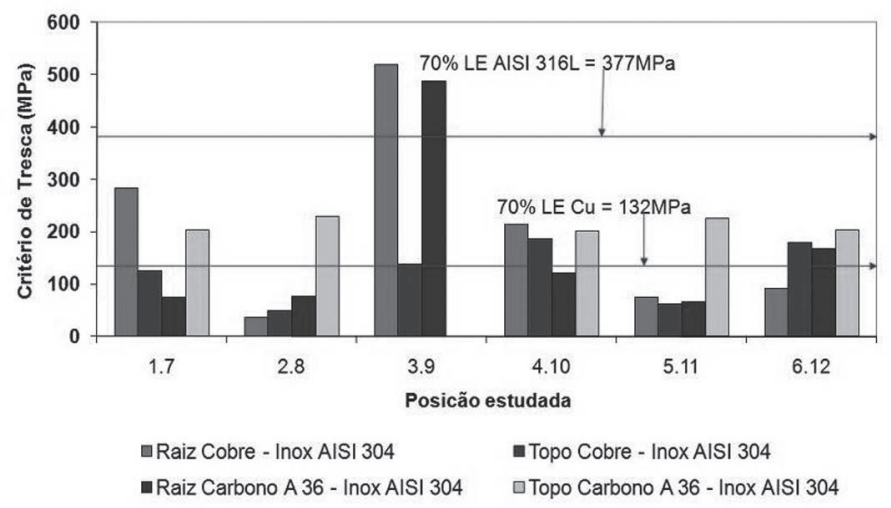

Figura 14. Valores das tensões residuais para os cordões de solda. Critério de Tresca. que as desenvolvidas no cordão de aço inoxidável AISI 316L.

As maiores tensões residuais nos cordões de solda ocorrem para as posições P3 (raiz da solda) e para a posição P9 (topo da solda). Ambos as posições estão no meio do cordão de solda conforme assinalado na Figura 15.

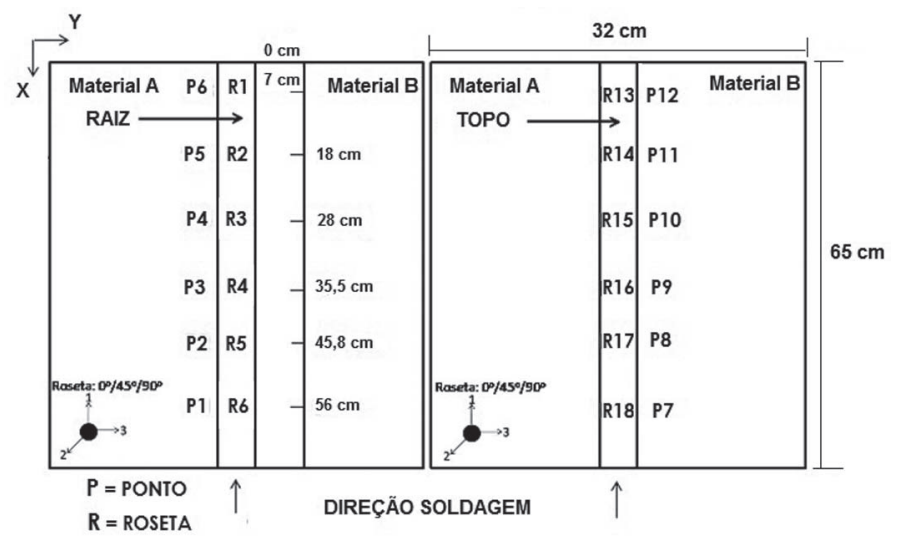

Figura 15. Localização das maiores tensões residuais. Critério de Tresca.

\section{Conclusões}

A partir das experiências realizadas pode-se concluir que:

a) As posições estudadas que apresentam os maiores valores para as tensões residuais uniformes equivalentes são as posições P3 e, P9, que estão localizados praticamente no centro das chapas soldadas, no material de adição e na raiz da solda. Seus valores de tensão máxima e mínima são ambos de tração.

b) Os maiores valores encontrados para as tensões residuais foram nos pontos situados no topo do cordão de solda.

c) As tensões residuais desenvolvidas durante o processo de solda dissimilar são maiores para a chapa de aço inoxidável AISI 304 do que as obtidas para o aço carbono A36.

Os quatro materiais estudados, aço carbono A36, aço inoxidável AISI 316L, aço inoxidável AISI 304 e cobre apresentam resultados que seguem a distribuição Log-normal para a vida de fadiga. Pôde-se observar que o comportamento da vida de fadiga para o cobre, aço carbono A36 e do aço inoxidável AISI $316 \mathrm{~L}$ é semelhante e que a tensão aplicada influi pouco para o número de ciclos que os corpos-de-prova suportam. $\mathrm{O}$ mesmo não ocorre para o aço inoxidável AISI 304 para o qual uma pequena variação da tensão aplicada altera significativamente a vida de fadiga.

\section{Agradecimentos}

Os autores agradecem à FAPEMIG, CDTN e UFMG-LRSS. 


\section{Referências Bibliográficas}

[1] ASTM. Standard Terminology Relating to Fatigue and Fracture testing. E 823-96, 2000.

[2] NETO, B. R.; COLOSIMO, E. A. Comparação de dois métodos para determinação do limite de resistência à fadiga do aço ASTM A - 515. Relatório do Departamento de Estatística UFMG, 1999.

[3] COLLINS, J. A. "Failure of materials in mechanical design”, John Wiley \& Sons, USA, 1993.

[4] BUENO, D. P. Estudo do comportamento em fadiga do aço inoxidável AISI 316L através da análise dos parâmetros geométricos das bandas de deslizamento persistentes. Dissertação de mestrado, UFRGS, 1996.

[5] METALS HANDBOOK. Failure Analysis and Prevention - Vol. 10. American Society for Metals, $8^{\mathrm{a}}$ ed., Metals Park, Ohio, 1975.

[6] JOSEPH, A., SANJAI K. RAI; JAYAKUMAR, T.; MURUGAN, N.. Evaluation of residual stresses in dissimilar weld joint. International Journal of Pressure Vessel and Piping 82, 2005 .

[7] A. ASTEUWER, A.; PEEL, M. J.; WITHERS, P. J.; Dissimilar friction stir welds in AA5083-AA6082: The effect of parameters on residual stress. Materials Science and Engineering A 441,2006.

[8] ASTM Standard Test Method for Determining residual Stresses by Hole-Drilling Strain-gage Method. E 837-01,2002.

[9] VISHAY MICRO-MEASUREMENTS; Tech Note TN503-6, 2006.

[10] ASM, Welding, Brazing, and Soldering, Metals Handbook, Vol 6, American Society for Metals, 1994.

[11] Minitab, versão15. 